\title{
Enhancement of Sugarcane Production by Counteracting the Adverse Effects of Climate Change in Sindh Province, Pakistan
}

\author{
Bilal Ahmad ${ }^{1}$ and Yan Yunxian ${ }^{1}$ \\ ${ }^{1}$ Affiliation not available
}

November 6, 2020

\begin{abstract}
In Pakistan sugarcane is an important cash crop, a source of income and employment for the farming community. The environmental degradation results in the increased frequency and intensity of extreme weather events has significant consequences for sugarcane production in the world, especially in the developing countries like Pakistan, because of relatively low adaptive capacity, high vulnerability to natural hazards, and weak forecasting systems and mitigating strategies. This paper is an attempt to analyze the impact of environmental change on sugarcane production in Sindh province of Pakistan. Qualitative and quantitative data approach were adopted for the analysis and the data is collected through exploratory design, case study, and survey design. The sample consists of sugarcane growers, i.e., landowner farmers, ex-farmers, and employed farmers. The results based on multiple regression model indicated that only three factors (rainfall, soil conditions, and irrigation) have significant effect on the production of sugarcane. Some suggestions and implications are mentioned based on empirical findings.
\end{abstract}

Title: Enhancement of Sugarcane Production by Counteracting the Adverse Effects of Climate Change in Sindh Province, Pakistan.

Bilal Ahmad,

College of economics and management jilin agricultural university, Changchun china.

Ahmadbilal610@ymail.com

Yan yunxian

College of economics and management jilin agricultural university, Changchun china.

Yanyunxian@126.com

\section{Abstract:}

In Pakistan sugarcane is an important cash crop, a source of income and employment for the farming community. The environmental degradation results in the increased frequency and intensity of extreme weather events has significant consequences for sugarcane production in the world, especially in the developing countries like Pakistan, because of relatively low adaptive capacity, high vulnerability to natural hazards, and weak forecasting systems and mitigating strategies. This paper is an attempt to analyze the impact of environmental change on sugarcane production in Sindh province of Pakistan. Qualitative and quantitative data approach were adopted for the analysis and the data is collected through exploratory design, case study, and survey design. The sample consists of sugarcane growers, i.e., landowner farmers, ex-farmers, and employed farmers. The results based on multiple regression model indicated that only three factors (rainfall, soil conditions, and irrigation) have significant effect on the production of sugarcane. Some suggestions and implications are mentioned based on empirical findings. 
Keywords: Climate Change; Environmental Degradation; Exploratory Design; Multiple Regression

\section{Introduction}

Agriculture is an important sector of Pakistan's economy. This sector directly supports the country's population and accounts for $26 \%$ of its GDP. The rising population puts pressure on agriculture to improve production to meet the increased demand. Sugarcane is an important cash crop in Pakistan. A C4 crop, it mainly grows in the tropic and sub-tropic regions and is an important source of bioenergy and sugar in the world. Sugarcane is a perennial crop cultivated on 20 million ha with an annual yield of approx. 1325 million tons, which is used for sugar, energy, rum, and chemicals (Saunders 2009). Sugarcane is one of the world's major food-producing crops, providing about $75 \%$ of sugar produced in the world for human consumption (Dehlavi, Groom, and Gorst 2015). During 2015-2016, sugarcane was cultivated on 1132 thousand ha,as compared 1141 thousand ha of the previous year in Pakistan, which produced 65,475 thousand tons (Muslehuddin and Faisal 2006). The total cultivated area and production of sugarcane in Pakistan is given in Figure 1.

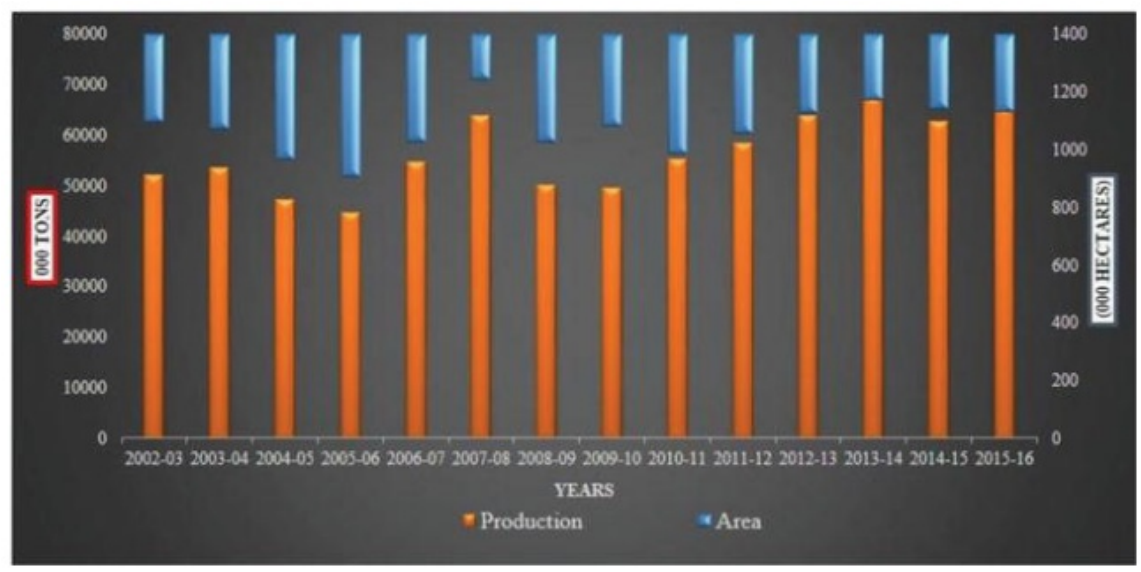

Figure 1.Total area and production of sugarcane in Pakistan (2002-2016).

Source.Pakistan Bureau of Statistics (2016).

Several countries are considered as leading sugarcane producers, including Columbia, where 123.0 tons ha-1 are produced, Australia, Egypt, and the USA produces 99.3, 87.3, and 74.6 tons ha-1 respectively (Devaraja 2008). Pakistan produces around 43 tons ha-1, which is relatively small as compared to the other leading sugarcane producing countries. In Pakistan, sugarcane is produced in the regions of Sindh, Khyber Pakhtunkhwa (KPK), and Punjab, among which Punjab ranks first in sugarcaneproduction (Ur-Rehman, Wassan, and Dost 2012).

Sugarcane is not only a source of income for sugar manufacturers but also for several people in Pakistan who resell sugars and sugar products. Sugarcaneis the source of income for about $64 \%$ of the total agricultural output in Sindh(Haq et al. 2013). A total of 91 sugar mills are located in Punjab, 48 in Sindh, and nine in KPK. These sugar mills produce approximately 3.2 million tons of sugar, to meet Pakistan's demand. There is a significant gapbetween the quantity in whichsugarcaneis produced and the requirement. This gapmay be attributed to bad farming practices, environmental conditions and other conditions that could include the lack of government and other stakeholder facilities (Rana 2018).

Climate change has various causes, but all of them do not impact the production of sugarcane in all regions (Economic Survey of Pakistan 2007). It is true that identification of the primary factors, including climate change, that hinder sugarcane production is necessary. Still, studyingstrategies and measures to address the negative impacts of climate change in Pakistan is far more critical. The main objective of this research is 
to analyze sugarcane production problems in Sindh, as the sugarcanefarmers face climate change issues and how they can be effectively handled. This study is based on primary data, obtained from the survey, and secondary data that include relevant studies to climate change and sugarcane production. In reality, it is not possible to eliminate the adverse effects of global warming;still, these steps and techniques can be adapted to the unfavorable climate changes impacts on sugarcane production. This study, therefore, examines the particular problems that undermine the capacity of sugarcane production in the Sindh province of Pakistan.

\section{Literature review}

Approximately $70 \%$ of the Pakistani population is linked directly and indirectly to agriculture.Businesses produce raw materials and fertilizers for farmers; some companies use agricultural products; and farmers earn their sustenance (Rana 2018).

The temperature effects on the rate and efficiency of photosynthesis are directly linked to the growth of crops. Studying air temperatures between 34 and $5{ }^{\circ} \mathrm{C}$, Waldron, Glasziou, and Bull (1967) observed a linear decrease in the efficiency of photosynthesis. Sugarcane needs optimal temperature,otherwise the yield is reduced. Extreme temperatures cause a severe reduction in the yield of sugarcane due to its physiology, biochemistry, and quality, which lead to poor agricultural products. During planting, low or high temperature influences germination, cultivation, and the viability of early growing crops such as sugarcane which are dependent on the temperature. Several experimentshave been carried out to boost the quality of sugarcane at high and low temperatures.Stender (1924) showed a close relationship between the stalk's length and diameter and air temperature, with a drop of one-third in the growth rate in the winter against that observed in summer. The reduction in stalk growth rate, either in length or diameter, is followed by an increase in the rate of sucrose accumulation. The physiological ripening process of sugarcaneis dependent on the seasonal reduction in air temperature, which slows growth rates(Alexander, 1973; Mamet \& Galwey, 1999). However, this decline in the levels of growth does not affect the photosynthetic process significantly. This can make it possible to prevent further photosynthesis. Cardozo (2012) noted an inversely proportional relationship between air temperature and sugarcane ripening, with higher correlation coefficients found when the air temperature was measured 120-150 days before sampling, which is in accordance withthe findings of Clement (1962).

Glasziou et al. (1965) found that when the air temperature reduced over a long period, high sugar content was achieved. According to them when the air temperature is constant or when minor normal temperature fluctuations occur, sugar concentration does not reach $12 \%$ of the fresh weight. However, when the average air temperature decreases over a long period, that is, three to six months, the concentration of sugar exceeded $17 \%$ of the fresh weight. There is no consistency among researchers about the thermal parameters for sugarcane, which are primarily related to the base temperatures, as various baseline temperature values are proposed which may differ depending on the location, cultivars, and phenological process (Scarpari andBeauclair 2004).

Barnes (1964) considered the basic shooting temperature to be $12{ }^{\circ} \mathrm{C}$, while Inman-Bamber (1994) found a base temperature of $16{ }^{\circ} \mathrm{C}$ for tillering.Bacchi and Souza (1977) reported values between 18 and $19{ }^{\circ} \mathrm{C}$ for the internode elongation period. The earliest cultivars (SP91-1049 and SP86-155) were higher in ripening of sugarcane, varying between 20 and $21^{\circ} \mathrm{C}$, whilethose in the middle (RB867515) werelower ripening cultivars (SP 83-2847), between 18 and $19{ }^{\circ} \mathrm{C}$, as examined by Cardozo (2012), who found discrepancies in the base temperature. According to Cardozo (2012), the higher the base temperature, the smaller the rate of growth under low air temperature, explaining the precocity of specific crops in comparison to others. Late cultivars are less sensitive to low air temperature than the early ones; they continue their growth for longer periods, thus delaying their ripening.

Various reforms to boost agricultural markets in the undeveloped countries have been addressed in previous studies but the environmental aspect of these reforms has been skipped. Improvements need to be made with concerted steps to tackle the detrimental side of climate change as the implications of climate change cannot be avoided. A study related to sugarcane production was conducted in 2003. The results suggested that sugarcane should be used as a substitute for sweeteners instead of exporting it as a raw material. The 
study was carried out using Policy Analysis Matrix (PAM), Domestic Resource Costs (DRC), and social benefits and cost (SBC) analysis, which supported sugarcane's competitiveness in Pakistan (Khan, Farooq, and Saddozai 2006).

Tayyab et al. (2018) examined some of the bacterial diseases that occurred in crops because of climate change. Their study confirms the need of high quality fertilizers to deal with bacterial attacks on sugarcane. The occurrence of diseases is partly due to the climate change in Pakistan.

While several reasons have been identified for the poor production of sugarcane in Pakistan, environmental factors have been ignored. The survey introspected several of the reasons,for instance, high cost of land, unskilled labor, and lack of extension services, adequate training for farmers, and access to financial facilities in rural areasapart from prevalence of conventionaltechniques and methods as well as little information regarding marketing. Despite the existence of several policies and programs of the Government of Pakistan for farmers, a focus on environmental factors is lacking, whereas this cannot be managed instantly as it requires time and effort.(Bhutta, Ilyas, and Usman, 2019). In Pakistan, the potential for producing sugarcane on a large scale is very high, but due to several reasons and factors, actual production is below average.

Sugarcane goes through two critical phases, growing phase and ripening phase. In the first phase, bright sun with high humidity as well as an optimum level of rainfall are required, while during the ripening phase, dry weather with less precipitation is needed; otherwise, the yield will be damaged (Girei and Giroh 2012).Also, saline soil is not suitable for sugarcane production (Husain and Khattak 2011). The $\mathrm{pH}$ level in water as well as high nutrients in the soil play a significant role in sugarcane growth and $\mathrm{pH}$ up to 8.5is tolerable (Sharif et al. 2014). Heat wave has increased in Pakistan due to high emission of $\mathrm{CO}^{2}$ and this has impacted the working conditions for sugarcane laborers,as sugarcane grows in bright sunlight with high radiations. High intense heat also contributes to rapid evaporationof water from the soil and plants which creates demand for more water for the production of sugarcane. Drought is also the major factor that affects crops,especially sugarcane yields, as tube wellsare not able to provide the required water and farmers depend on rainfall and canal water(Aslam 2016; Qureshi 2011). Because of the adverse effects of climate change, farmers need pesticides to counterclimate-related diseases. These pesticides are, on the other hand, sold at higher prices, (Bhutta, Ilyas, and Usman, 2019).

Many countries, including Pakistan, have been affected by the climate change. The causes of the intensified heat waves and climate changes worldwide are established, but to a certain degree, they are uncontrollable. In reality, $\mathrm{CO}^{2}$ increase can be regulated or decreased but cannot be entirely prevented (Qureshi et al. 2008). Climate change has many negative consequences in Pakistan that haveaffected almost every region and areas like forests, biodiversity, people and food production (Qureshi et al. 2010; Ur-Rehmanet al., 2012).

Several studies have been carried out on sugarcane production. Still, none of them addresses abiotic stress management practices (climate changes) to increase the production rates. According to Khan, Farooq, and Saddozai (2006), sugarcane has to be produced and consumed in Pakistan instead of being exported. Their study was based on an analysis of social benefits and resource costs. While Farid(2012) conducted a research in KPK, which show that the projects of farms are economically profitable and must be encouraged in Pakistan. This research was focused on a model of cost-benefit analysis, based on the data from surveys and did not cover the environmental factors.

A significant experiment was carried out by Khan, Khan, and Khan, (2012) to evaluate the cost-benefit analysis of sugarcane production. On the other hand,Husain and Khattak (2011) conducted a research to examine the relationship between sugarcane production and the various factors that included resources, labor, and marketing but ignored the environmental factors. Also, no study has been undertaken in which sugarcane growers' views and suggestions to reduce the ill effects of climate change were discussed. Based on the experimental design, in which secondary data was collected, Sharif et al. (2014) observed that white sugar is consumed more and should be produced moreto achieve more profit. This study does not answer what strategies and measures should be taken by sugarcane producers to deal with climate change. Indeed, suggestions and opinions of sugarcane growers of the Sindh region in Pakistan are worthy in dealing with 
climate change effects as they experience the impact of climate change directly. Pakistani government officials have reported that sugarcane production will decline in Sindh by the end of 2019. There is a higher volume of taxes and duties, but there is no strong evidence of environmental resistance (Sugarcane, 2018; Land Degradation in Sindh, 2002). In Pakistan $83 \%$ of the total sugarcane farmers are landowners but are not yet able to grow sugarcane in large, due to environmental factors(Cheema et al., 2019).

Many researchers have considered different factors responsible for carbon emissions. In these research studies, several factors of climate change that affects the agricultural sectorhave been investigated. Still, no specific research has been done on the specific issues of climate change in Sindh. These factors are major obstacles in achieving a high sugarcane growth, even when farmers use sophisticated modern technologies and are willing to invest in terms of time and money. Khan et al.(2012) assessed the relation between the production of sugarcane and different factors including capital,labor, and marketing, but their study did not cover environmental factors. So far, these studies have not considered what policies and steps should be made to cope with climate change factors. In reality, sugarcane growers from the region of Sindh in Pakistan have suggestions and views worth considering when dealing with the impact of climate change. In view of the above discussion, the main objective of this study are:

- To explore previous relevant studies and gather significant information regarding sugarcane production and related environmental factors (variable: climate change).

- To explore previous studies on sugarcane production in Pakistan to identify the independent variables (environmental factors).

- To conduct a survey in Sindh on farmers to investigate the relationship among independent variables and a dependent variable using an econometric model.

- Discuss measures and strategies to deal with the identified issues related to climate change in Sindh as per the targeted audience (farmers from the select region).

Purpose

Investigating the factors and obstacles related to climate change that underminethe growth of sugarcane production in Sindh.

Research questions

- What is the current situation and importance of sugarcane production in Pakistan?

- What are the environmental factors that could affect sugarcane production as per previous relevant studies?

- Which environmental factors affect sugarcane production in Sindh?

- How could we mitigate the identified adverse effects of climate change to enhance sugarcane production?

3. Materials and methods

3.1 Methodology

Three approaches, exploratory, case study, and survey design, have been used in this research. In the exploratory design, secondary data were collected on factors that are also considered to be independent variables in this study. For secondary sources, related journals and official reports were examined on sugarcane production and climate effects, prepared by the United Nations, various NGOs, and relevant government departments. After a detailed review of the previous studies, exploratory design assisted in formulating the survey questions and variables were chosen. Case study design helped to restrict the scope of the research by choosing only one region,Sindh, and targeting respondents in that region. The research topicis attuned toa case study design that is used to find a solution or to investigate specific issues in specific locations relating to specific objects. In this study, targeting just one region helped maintain the focus of the research. Survey method was used to obtain primary quantitative data for the econometric analysis to determine the relationship between variables (Jackson 2015). 


\subsection{Research approach and data collection}

This research is inductive in nature andrevealsthe issues related to the climate change problem in the Sindh region. There is no crucial work on the negative impact of climate change on sugarcane production in this region. No theory or model research was performed, but econometric analysis, which is predictive in nature, was chosen to find the relationship between the chosen variables. No hypothesis or model was tested to determine cause and effect, but the opinions of Sindh's sugarcane stakeholders were sought through a survey to predict the factor-to-sugarcane production relationship. Although several studies have investigated various factors affecting sugarcane production in Pakistan,environmental factors have not been specifically studied for Sindh. The primary data was gathered through the survey, while the secondary data was compiled from existing literature, includingjournal articles and official reports.

\subsection{Research population andsampling size}

The sugarcane growers have been regarded as researchers for this studysince they engage directly and observe climate change and are well aware of the sugarcane production situation in the region,which consists of cities and rural and coastal areas. There was no restrictionof age and gender of farmers in the selection of respondents. Sugarcane is produced in 23 areas in Sindhbut only five were targeted to reach the respondents because of accessibility problems. Weonly visited Hyderabad, Thurparker, Sukkur, Thatta, and Dadin, the main sugarcane producing areas. We used purposive sampling to target only knowledgeable farmers with at least three years of sugarcane farming experience. While the snowball sampling approach was used to reach the maximum number of respondents, some respondents suggested other people who worked in sugarcane farms and/or did sugarcane farming. Due to accessibility and convenience problems, 100 farmers were selected. Only 55 farmers replied to the survey, including farmers who owned the land, farmers who recently did sugarcane farming, and experiencedlabourerswho work in sugarcane farms.

The following formula was used to reach the actual targeted population:

Sample size $=(\text { Zscore })^{2} \times$ Standard deviation $\times(1-$ Std.Dev $) /(\text { margin of error })^{2}$

whereZ score for a $95 \%$ confidence level is 1.96 when the deviation is 0.5 , whereas the margin of error depends on the will of the researcher. Due to complexity issues, the original formula is written whereas the driven value for the formula is 384 when the confidence level is $95 \%$, and the margin of error is $5 \%$ (Saunders 2011).

Calculation: $384 \times 100 / 384+100-1=78$ (i.e., the sampling size for this study).

\subsection{Model}

In this analysis, a multi-regression model has been used.Model selection is based on the data related to development of sugarcane and climate impacts and these data are cross-sectional. This study aims to find issues which create obstacles for farmers in Sindhby testing the relationship among variables to determine the specific factors. In the survey, the respondents were rated according to their experiences regarding climate change issues. In contrast, their rating about the dependent variable reflects their acceptance of the current issue of sugarcane production. This work does not include unknown parameters, so OLS and related regression analysis techniques have been omitted from this study (Schlenker and Roberts 2006). There are several econometric models and each one has its own use and importance in forecastingthe relationship or cause and effect between variables to assist decision making regarding future. Cross-sectional data are obtained through a survey process, and these are new data acquiredas per research requirements. The standard formula for an econometric data analysis in this study is given below:

$$
Y=\partial_{0}+\beta_{1} X_{1}+\beta_{2} X_{2}+\beta_{3} X_{3} \ldots \ldots \beta_{8} X_{8}+\epsilon
$$



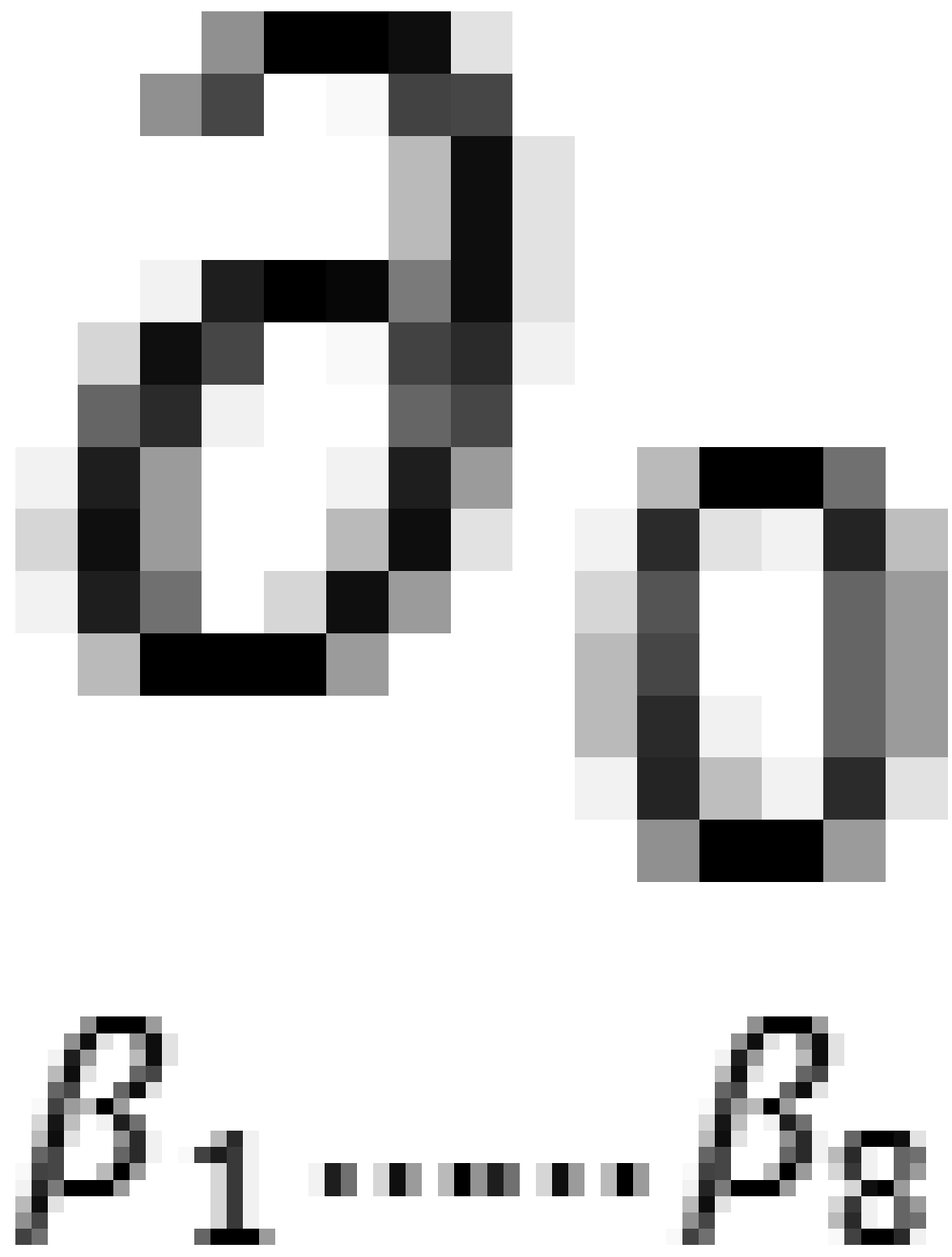


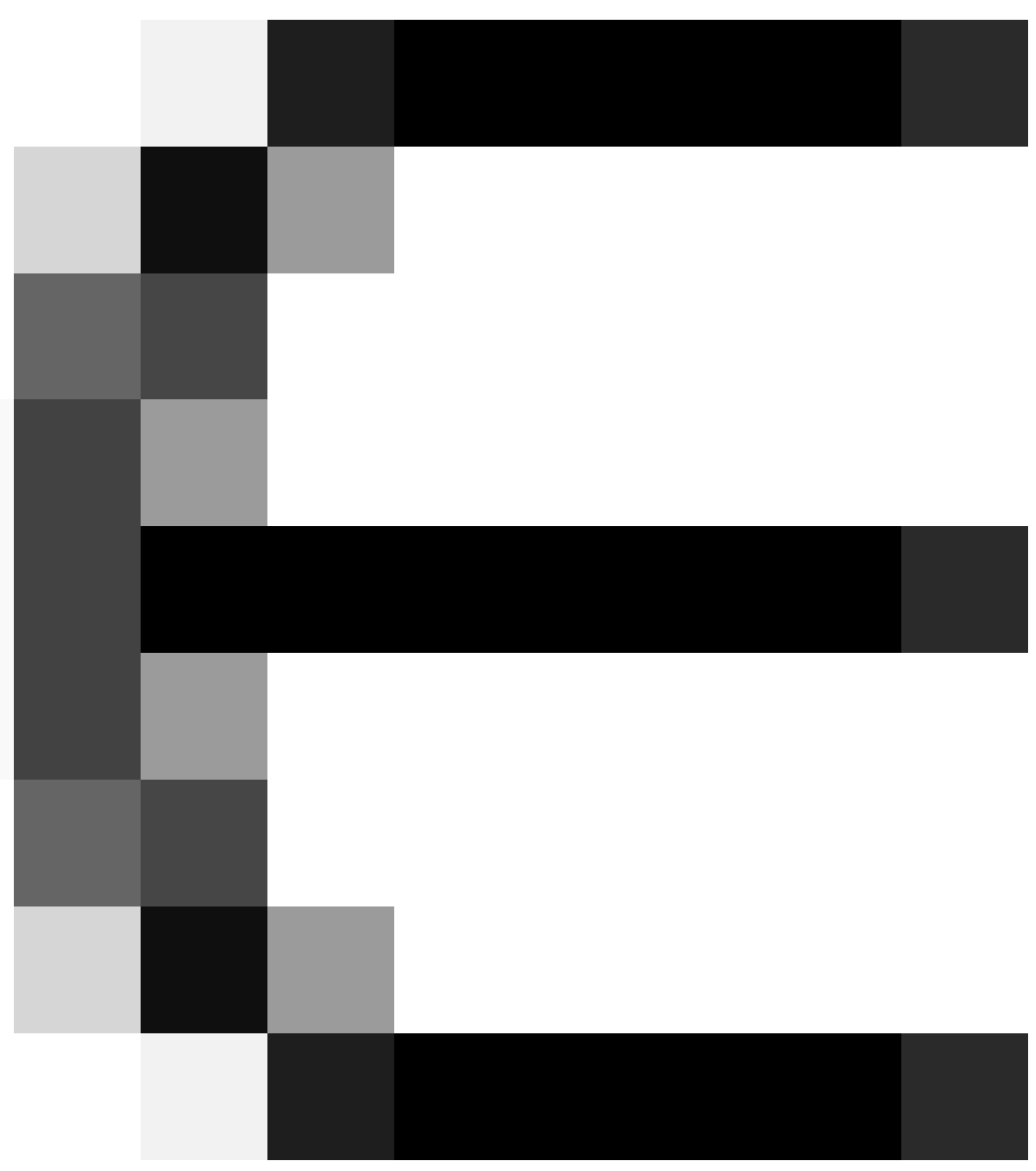


where $\mathrm{Y}$ is the dependent variable,

is the intercept,

are coefficients for the $\mathrm{X}$ independent variables, while is the error term. All variables and the reason for choosing eachare explained in Tables 1 and 2.

Table 1. Variables and targeted population

\begin{tabular}{lll}
\hline Variables & $\begin{array}{l}\text { Targeted Population } \\
\text { (Area-wise) }\end{array}$ \\
\hline $\begin{array}{l}\text { Dependent variable (Y): Decrease } \\
\text { in sugarcane production }\end{array}$ & $\begin{array}{l}\text { Dadin 10 Thatta 10 Hyderabad } 7 \\
\text { Tharparkar19 Sukkur 9 }\end{array}$ & $\begin{array}{l}\text { The rating was on a scale from 1 } \\
\text { to 10, in which 1 was indicated as } \\
\text { low level of answer satisfaction } \\
\text { about question. and 10 was the } \\
\text { highest level. The respondents } \\
\text { were rated as per the level of } \\
\text { impact. The independent }\end{array}$ \\
& $\begin{array}{l}\text { variables are quite common } \\
\text { climate change factors as per the } \\
\text { relevant studies irrespective of the } \\
\text { country. In contrast, the } \\
\text { dependent variable was chosen } \\
\text { because of the current prevailing } \\
\text { issue in Sindh regarding the } \\
\text { slump in sugarcane production. }\end{array}$ \\
& \\
$\begin{array}{l}\text { Independent variables }\left(\mathrm{X}_{n}\right): \\
\begin{array}{l}\text { Intense heatwave Irrigation } \\
\text { Floods Climate Change diseases }\end{array}\end{array}$ & \\
$\begin{array}{l}\text { Rainfalls Soil condition } \\
\text { Droughts Increase in water }\end{array}$ & \\
demand &
\end{tabular}

Table 2.Detailed explanation of the Independent variables and reason.

\begin{tabular}{ll}
\hline Variable & Explanation \\
\hline Decrease in sugarcane production & Current issue in Sindh. It assesses level of knowledge of the farmerson sugarcane cultiv \\
Intense heat & Sugarcane grows better in harsh summer which createsissues for farmers due to the lon \\
Irrigation & It assesses the need for improvements in the irrigation system as sometimes rainfall is n \\
Floods & It determines the condition of lands and of the groundwater. \\
Climate change diseases & It assesses the availability of pesticides, pricing issues, and the condition of the farmer' \\
Rainfall & It assesses the availability of water in case of shortage of rainfall due to climate change \\
Soil condition & It determines the condition of technical laboratories and technical awareness of farmers \\
Droughts & It assesses the condition of the irrigation system. \\
Increase in water demand & It estimates the shortage of water in case of extreme summer as high evaporation takes \\
\hline
\end{tabular}

We assumed that through the survey questionnaire farmers would respond to all climate change issues related to sugarcane production. They assessed the questions in the form of statements based on their experiences that helped us perform an econometric analysis to find the relationship between the variables.A multiple regression model was chosen to determine the power of independent variables related with the dependent 
variable. The outcome of this research could help the government of Pakistan stay focused on specific issues farmers deal with in the Sindh region. All problems of climate change must be tackled or other attempts must be made to keep the production of sugarcane on track in Sindh. Several studies have highlighted the factors discussed above, but the management of environmental factors takes time and a considerable effort. Most farmers were not educated, so the questions were translated into Urdu.

\section{Empirical results}

\subsection{Analysis of the results}

Table 3. Summary output

\section{Regression Statistics}

\begin{tabular}{ll}
\hline Multiple R & 0.993529 \\
R-square & 0.987099 \\
Adjusted R-square & 0.963901 \\
Standard error & 1.056963 \\
Observations & 55 \\
\hline
\end{tabular}

First of all, R-square value is 0.98 (Table 3), whichshows a high significance of the model in determining the relationship among the chosen variables. The high value of $\mathrm{R}$-square caused a high $F$-value (Table 4), which confirms that the null hypothesis is rejected, which makes the result significant. The value of the significance is more than 0.05, which is used as an overall value that is 5.3 (Table 4). Due to different respondents from different cities in this sample, the significance value shows the chances of difference between populations. Indeed, each farmer's experience is different. Instead of random sampling, purposive sampling was used to target only farmers. The regression value also indicates that we have discarded the right prediction as a Y-intercept value.

Table 4. ANOVA.

\begin{tabular}{llllll}
\hline & Df & SS & MS & F & $p$-Value \\
\hline Regression & 8 & 4017.493 & 502.1866 & 449.5161 & $5.39 \mathrm{E}-41$ \\
Residual & 47 & 52.50707 & 1.117172 & & \\
Total & $\mathbf{5 5}$ & $\mathbf{4 0 7 0}$ & & & \\
\hline
\end{tabular}

The goal of the research is also to establish a strong relationship between different farmers of sugarcane in Sindh. We required a perfect prediction of the link without using the independent variable coefficient to predict $Y$, which is usually the case in time series data. The coefficient of the independent variables in this investigation, which justifies removing constant interception value, is useless due to the cross-sectional data obtained by the survey. Another reason for eliminating the intercept value is that we have not changed the dataand have ensured that all independent variables are used during theregression, while Y-intercept is used to remove the data distortion when the researcher deletes some variable. Intercept value also help define the path of independent variable curves in the slope graph, which is not used in this study due to a smaller sample size (55 observations) and the nature of the research. After removing the intercept value, the model shows perfect results for the relationship between the selected variables. The $p$-values for independent variables (Table 5) show that irrigation, rain, and soil are in particular issues for farmers in Sindh. At the same time, other factors that also influence climate change factors in Sindhcan be examined in a further study, but they do not affect the sugarcane production in Sindh. The $p$-values of other factors are higher than 0.05 , meaning they are not significant as per the survey data, which includes intense heat, floods, climate change diseases, droughts, and increase in water demand. 
Table 5. $p$-Values of independent variables.

\begin{tabular}{lllllll}
\hline & Coefficients & Standard Error & $t$-Stat & $p$-Value & Lower 95\% & Upper 95\% \\
\hline Intercept & 0 & $\# \mathrm{~N} / \mathrm{A}$ & $\# \mathrm{~N} / \mathrm{A}$ & $\# \mathrm{~N} / \mathrm{A}$ & $\# \mathrm{~N} / \mathrm{A}$ & $\# \mathrm{~N} / \mathrm{A}$ \\
Intense heat & 0.044107 & 0.090724 & 0.486166 & 0.629109 & -0.13841 & 0.226619 \\
Irrigation & 0.49208 & 0.125712 & 3.914325 & 0.000291 & 0.239179 & 0.74498 \\
Floods & -0.01745 & 0.046635 & -0.37417 & 0.709962 & -0.11127 & 0.076369 \\
Climate change diseases & 0.065635 & 0.080094 & 0.819479 & 0.41665 & -0.09549 & 0.226764 \\
Rainfalls & 0.407089 & 0.10939 & 3.721436 & 0.000529 & 0.187024 & 0.627154 \\
Soil condition & 0.154199 & 0.074689 & 2.064546 & 0.044509 & 0.003944 & 0.304454 \\
Droughts & 0.277804 & 0.192785 & 1.441006 & 0.156212 & -0.11003 & 0.665638 \\
Increase in water demand & -0.03108 & 0.06655 & -0.46705 & 0.642625 & -0.16496 & 0.1028 \\
\hline
\end{tabular}

The dependent variable is related to a specific climate change problem that affects the agriculture sector regardless of the area, while independent variables are evaluated differently for each area. All the factors chosen are affected byclimate change, but during the research, only particular factors that are common to all farmers in the selected areas in Sindh were highlighted.

\section{Discussion}

From the analysis it seems only three factors, rainfall, soil conditions, and irrigation, act as a hindrance to sugarcane production in Sindh (as the $p$-values are less than 0.05). The $p$-values of other factors are greater than 0.05 , which means they are not significant. The $t$-values of irrigation, rainfall, and soil condition are higher than 2.04 , which are normally used as standard values. The other values are lower than 2.04 , so they were rejected as null hypothesis. Climate change diseases was found null hypotheses which shows that in Sindh, farmers use pesticides to deal with crop diseases occurring due to change in the climate. Such pesticides are sold at higher prices,but this factor was not rated as significant by all farmers. In fact, the $p$-values and $t$-values show that irrigation, rainfall, and soil condition are positively related to the decrease in sugarcane production in Sindhthat's why other factors are undiscussed. Other factors cannot be ignored, but this research aims to investigate the specific issues faced by sugarcane farmers in Sindh. Thus, only such factors that would helpin facilitating sugarcane farming in Sindh are considered for discussion. The sugarcane production situation is unsatisfactory and needs the current government of Pakistan to take urgent steps, otherwise things will get worse. Regarding irrigation, water is not adequate for sugarcane production due to poor infrastructure (such as tube wells) in the chosen areas (Qureshi 2011). Participants accepted that unavailability of water harms sugarcane production as the precipitation mechanism is affected. In Sindh, the rainfall was normalcompared to other regions of Pakistan.However, the rainfall percentage has decreasedof late which has compelled farmers to rely oncanal, ground and tube well water. In Sindh, precipitation accounts only for $20 \%$ of the overall sugarcane production requirements. The condition of the irrigation system is not satisfactory even though there are several development plans that have already been implemented (Qureshi 2011).

The current findings could assist public officials in addressing specific issues instead of covering an extensive list of climate change factors. Most of the farmers in Sindh use salt-rich water,which is detrimental to sugarcaneyield, and they use this water from the nearby drainage systems at least to moisturize the crops. Sindh Irrigation and Drainage Authority (SIDA) is accused of unfair treatment to the farmers and,in some areas, irrigation problem is created because the irrigation department facilitate rich landowners by diverting the water from the canals (Land Degradation in Sindh, 2002). This allegation seems to be true to some extent.Farmers mostly pointed out that unavailability of water damages sugarcane yield to a great extent. Installation of tube well privately is way too expensive for any farmer.Since the government of Pakistan also earns through taxes and duties on sugarcane, itbecomes the responsibility of officials to install tube wells. 
Drought was not considered to be a significant factor in this research, which means that canal water is available to the farmers. However, farmers still rely on tube wells that are not good for sugarcane yields due to the salinity and other detrimental properties of the groundwater. Canal water should be channeled appropriately and as the second alternative, which in reality is not suitable, is tube well installation. Most farmers have closed sugarcane production companies due to lack of water, as rainfall contributeslittle to the agriculture in Sindh. At present, new reservoirs need to be developed in the vicinity of areas that contribute to the production of sugarcane and use technologies that make groundwater suitable for sugarcane because groundwater is the only option left to the farmers in Sindh after canal water.Participants said that their sugarcane production has been severely affected due to less rainfall.

Intense heat is not a substantial factor in this research, but the increase in temperature means that sugarcanewould require more water as evaporation increases. Lack of rainfall affects sugarcane yields since water availability in Sindh is limited. Still, large-scale forestation can help reduce heatwaves in sugarcane production areas asdeforestation has affected the pattern of rainfall all over the world and which is one of the reasons for less and heavy rainfall, sometimes causing floods (Shakoor et al. 2011). Small-scale deforestation also affects the climate of specific region in small areas. (Dehlavi et al. 2015).In the Sindh region, forests must be grown near the sugarcane fields to maintain the average rainfall precipitation.

The soil condition of sugarcane production in Sindh was also considered unsatisfactory by the participants. Soil conditions are the primary factor that farmers consider when choosing the right land for a sugarcane crop. Salinity undermines the potential of the soil by depositing salt in the soil, which is reported to have been filed at 120 million tons each year in the soil of which only $20 \%$ goes back to the sea. Salinity is due to groundwater, as most farmers use tube wells as the main source of water, but the drainage system in rural areas is aninfluentialfactor for irrigation. Wastewater is absorbed into the ground from the drainage system and increases the level of underground water, which results in water logging. (Ur-Rehman et al. 2012).Also called over-irrigation, the deep water often reaches the surface. The drainage system needs to be given greater importance in at least those areas where sugarcane is grown on a large scale. The technical labs in Sindh, which provide technical assistance in evaluating the soil condition, do not necessarily help, but rather highlight soil problems. According to a study, every year 40,000 hectaresof fertile land becomes saline, of which a majority percentage belongs tothe Sindh region alone. Roughly $57 \%$ of Sindh has beenwaterlogged, which is a direct indication of the government's inability of installing adequate and efficient drainage systems in rural areas. Practices of soil management are vital for making the soil fertile for sugarcaneproduction, which calls for serious government efforts to initiate programs to educate the farmers of Sindh to deal with challenges such as use of fertilizers.

\section{Conclusions}

The primary purpose of this research was to explore how the issue of climate change in Sindh can be handled effectively in connection with sugarcanefarmers. This research is based on primary data from a survey and secondary data including related studies on climate change and growthof sugarcane production. To this end, on the basis of the empirical findings, we conclude that in comparison with other factors addressed in several previous studies, environmental factors should be prioritized in overcoming the less growth in sugarcane production. The various factors include technical factors, economic factors, and social factors, but environmental factors, as discussed in this research, need time to manage them through effective strategies. The outcome is not immediate, but the causes of climate change need to be tackled first, particularly the three significant factors found in this study. Rise in the production of sugarcane depends only on a favorable climate rather than on social and financial factors. Instead of focusing on all climate change factors, we emphasize the formulation of measures and strategies to resolve clearly defined issues to provide a favorable environment for the farmers for alarge-scale sugarcaneproduction with confidence. The cross-sectional survey data collected here prove that the effects of climate change cannot be overcome overnight. They require serious efforts and effective actions to restore the average sugarcane production at least in Sindh. The increase in production will come as time passes, but immediate action must be taken to deal with the three main factors discussed above. This study does not include all the steps and approaches needed for further 
research since it highlights only the most relevant questions for Sindh's sugarcane producers. The review is entirely reliable for a future study, but certain drawbacks need to be addressed. The first constraint was the targeted areas, as only a few areas of Sindh could bechosen because of accessibility issues. The second limitation is the sample size that does not reflect all farmers of Sindh. The third constraint is the time factor that might be taken into considerationin future if social issues and other environmental factors are known. The study covers a small range of environmental factors, which does not take inti account other facts and figures, such as initiatives by the current Pakistani government, climate change figures for Sindh, and the reasons for soil damage in Sindh. For this analysis, the following three variables may be used as a basis for further research: rainfall, soil conditions, and irrigation. Research is also needed to develop effective and appropriate measures and strategies to address the identified factors that would help Pakistan government to address these issues specifically. The issues raised as a result of climate change differ from region to region in Pakistan, and as a main contribution, this research has identified specific issues for sugarcane farmers in Sindh.

Technical knowledge and assistance may help sugarcane producers deal with unusual damages and environmental issues. Monetary assistance can be made available in the form ofloans to farmers, whileNGOs can reach out to thefarmers to assist with new technological knowhow. While lack of advance technologycan harm the growthof sugarcane production, the availability of the same could handle the damage caused to the environment. However, when farmers are technologically advanced and have advanced knowledge, they could easily manage environmental damage such as disease attacks. Astudy by Abdul et al. (2012) showed that climate change has an impact on agricultural production, but it is not necessary for every outcome of climate change to affect crop production;technological advancementmay be made in the fight against increases in $\mathrm{CO}^{2}$ due to climate change (Abdul et al. 2012). Although it is difficult for the government to meet all the criteria or make all relevant schemes more accessible to all,certain subjective measures such as planting of trees in agricultural areasare in place to cope with heatwaves. Specific problems such as highdemand of water for irrigation are due to the heatwave situation, as evaporation increases during high temperatures. In Pakistan, heatwavesare a rampant environmental problem which iscreated due to elevated $\mathrm{CO}^{2}$ levels, and this has affected the growth of sugarcanefarming, as sugarcane needs intense heat to grow (Ehsanullah et al. 2011; Ghaffar et al. 2012). Due to the adverse effects of climate change, farmers need pesticides to cope with diseases. However, the cost of these pesticides is high, which preventsthem from buying them, and this leads to the farmers resorting to the cultivation of disease-affected sugarcane crops (Chohan et al. 2013).

\section{Data Accessibility:}

\section{Climate data and mixent file: Dryad DOI: https://doi.org/10.5061/dryad.x3ffg7h7.}

\section{References}

Abdul, Ghaffar, Akbar Nadeem, SH Khan, Jabran Khawar, RQ Hashmi, Iqbal Asif, and MA Ali. 2012. "Effect of trench spacing and micronutrients on growth and yield of sugarcane (Saccharum officinarum L.)." Australian Journal of Crop Science 6 (1):1-9.

Ahmad, Manzoor, Zahoor Ul Haq, Zeeshan Khan, Shoukat Iqbal Khattak, Zia Ur Rahman, and Shehzad Khan. 2019. "Does the inflow of remittances cause environmental degradation? Empirical evidence from China." Economic research-Ekonomska istraživanja 32 (1):2099-2121.

Aslam Cheema, Muhammad Waqas, Riaz Ahmad, Abdul Khaliq, and Rashid Ahmad. 2019. "Improving the productivity and sugar recovery of cane by potash nutrition under different planting methods." Pakistan Journal of Agricultural Sciences 56 (3).

Aslam, Muhammad. 2016. "Agricultural productivity current scenario, constraints and future prospects in Pakistan." Sarhad Journal of Agriculture 32 (4):289-303.

Alexander, AG. 1973. Sugarcane Physiology. Elsevier, Amsterdam, Netherlands.

Bhutta, Ehsan, Muhammad Ilyas, and Muhammad Usman. 2019. "The need for transforming agriculture 
produce markets: evidence from Punjab, Pakistan." Pakistan Journal of Agricultural Sciences 56 (3).

Cardozo, NP. 2012. "Modeling sugarcane ripening as function of meteorological variables." Journal of Science and Agricultural Meteorology .

Chohan, Muhammad, Ubedullah Anwar Talpur, Riaz Noor Pahnwar, and Saifullah Talpur. 2013. "Effect of inorganic NPK different levels on yield and quality of sugarcane plant and ratoon crop." International Journal of Agronomy \& Plant Production4:3668-3674.

Damodar, N. (2003). Basic econometrics. (4 ${ }^{\text {th }}$ ed.). Mc graw Hill: pp. 17-297.

Dehlavi, A, B Groom, and A Gorst. 2015. "Climate change adaptation in the indus ecoregion: a microeconometric study of the determinants, impacts, and cost effectiveness of adaptation strategies." World Wide Fund for Nature (WWF) Pakistan, Islamabad .

Devaraja, TS. 2008. "Cost of Production of Sugar from Sugarcane in Karnataka-A Comparative Analysis Approach." COOPERATIVE SUGAR 39 (6):15.

Ehsanullah, K Jabran, M Jamil, and A Ghaffar. 2011. "Optimizing the sugarcane row spacing and seeding density to improve its yield and quality." Crop Environ 2:1-5.

Farooqi, Anjum Bari, Azmat Hayat Khan, and Hazrat Mir. 2005. "Climate change perspective in Pakistan." Pakistan J. Meteorol 2 (3).

Farid, J. 2012 Economic viability of farm project in KPK Pakistan. "Central university Research Journal " $3(2): 2$.

Ghaffar, A, Ehsanullah, N, Akbar, SH, Khan, R, Qamar, K, Jabran, A, Iqbal and MA Ali. 2012. Effect of trench spacing and micronutrients on growth and yield of sugarcane (Saccharum officinarum L.). ' 'Australian Journal of Crop Science 6:1-9.

Girei, AA, and DY Giroh. 2012. "Analysis of the factors affecting sugarcane (Saccharum officinarum) production under the out growers scheme in Numan Local Government Area Adamawa State, Nigeria." Journal of Education and Practice 3 (8):195-200.

Glasziou, KT, TA Bull, MD Hatch, and PC Whiteman. 1965. "Physiology of sugar-cane VII. Effects of temperature, photoperiod duration, and diurnal and seasonal temperature changes on growth and ripening." Australian Journal of Biological Sciences 18 (1):53-66.

Haq, Aban, Amal Aslam, Aqeel Akbar Chaudhry, Asad Naseer, Kabeer Muhammad, Khalid Mushtaq, and Maheen Saleem Farooqi. 2013. "Who is the 'arthi': Understanding the commission agent's role in the agriculture supply chain." International Growth Centre (IGC) Working Paper .

Husain, Anwar Hussain, and Naeem Ur Rehman Kjhattak Khattak. 2011. "Economic analysis of sugarcane crop in district Charsadda."

Inman-Bamber, NG. 1994. "Effect of age and season on components of yield of sugarcane in South Africa." Proceedings of the South African Sugar Technologists Association.

Jackson, Sherri L. 2015. Research methods and statistics: A critical thinking approach : Cengage Learning.

Khan, Asghar Ali, Muhammad Ayaz Khan, and Qudratullah Khan. 2012. "Economic analysis of sugarcane (Saccharum officinarum L.) intercropping with canola (Brassica napus L.)." Pak. J. Agri. Sci 49 (4):589-592.

Khan, Asif, Arshad Farooq, and Khuram Nawaz Saddozai. 2006. "Comparative Advantage Of Sugarcane Production In Pakistan." Bangladesh Journal of Agricultural Economics 29 (454-2016-36543):69-79.

Land degradation in Sind. Available online: https://www.dawn.com/news/62696 ( Accessed on 21 Oct 2002). 
Mamet, LD, and NW Galwey. 1999. "A relationship between stalk elongation and earliness of ripening in sugarcane." Experimental Agriculture35 (3):283-291.

Muslehuddin, Muhammad, and Nadeem Faisal. 2006. "Long range forecast of Sindh monsoon." Pakistan Journal of Meteorology 3 (5).

Mohammad, Hussain, Khan. "Sugarcane production in Sindh is about to decline," DAWN, September 27, 2018, https://www.dawn.com/news/1435151.

Pakistan, Go. 2010. "Economic survey of Pakistan." Economic Affairs Wing, Finance Ministry, Islamabad

PERVAIZ, UROOBA, F Khan, D Jan, and M Zafarullah. 2013. "An Analysis of Sugarcane Production With Reference to Extension Services in Union Council Malakandher-Peshawar." SJA 29 (1):37-42.

Qureshi, Asad Sarwar. 2011. "Water management in the Indus basin in Pakistan: challenges and opportunities." Mountain Research and Development 31 (3):252-260.

Qureshi, Asad Sarwar, Peter G McCornick, Manzoor Qadir, and Z Aslam. 2008. "Managing salinity and waterlogging in the Indus Basin of Pakistan." Agricultural Water Management 95 (1):1-10.

Qureshi, Asad Sarwar, Peter G McCornick, Asrar Sarwar, and Bharat R Sharma. 2010. "Challenges and prospects of sustainable groundwater management in the Indus Basin, Pakistan." Water resources management 24 (8):1551-1569.

Rana, Muhammad Ahsan. 2018. Commissions and Omissions: Agricultural Produce Markets in Pakistan. Working Paper 01.

Saunders, Mark NK. 2011. Research methods for business students, 5/e : Pearson Education India.

Scarpari, Maximiliano Salles, and Edgar Gomes Ferreira de Beauclair. 2004. "Sugarcane maturity estimation through edaphic-climatic parameters." Scientia Agricola 61 (5):486-491.

Schlenker, Wolfram, and Michael J Roberts. 2006. "Nonlinear effects of weather on corn yields." Review of agricultural economics 28 (3):391-398.

Shakoor, Usman, Abdul Saboor, Ikram Ali, and AQ Mohsin. 2011. 'Impact of climate change on agriculture: empirical evidence from arid region." Pak. J. Agri. Sci 48 (4):327-333.

Sharif, Muhammad, Muhammad Azam, Abdul Jabbar Niazi, and Sajida Taj. 2014. "Financial profitability of white sugar production in Pakistan." Pakistan Journal of Agricultural Research 27 (3).

Stender, HK. 1924. "Some sugar cane growth measurements." Hawaiian Planters' Record 28:472-495.

Tayyab, Muhammad, Waqar Islam, Yasir Arafat, Ziqin Pang, Caifang Zhang, Yu Lin, Muhammad Waqas, Sheng Lin, Wenxiong Lin, and Hua Zhang. 2018. "Effect of sugarcane straw and goat manure on soil nutrient transformation and bacterial communities." Sustainability 10 (7):2361.

Waldron, JC, KT Glasziou, and TA Bull. 1967. "The Physiology of Sugar-Cane. IX. Factors Affecting Photosynthesis and Sugar Storage." Australian Journal of Biological Sciences 20 (6):1043-1052. 